\title{
Pelvis metastasis from primary choroidal melanoma: a case report
}

This article was published in the following Dove Press journal:

OncoTargets and Therapy

14 November 2014

Number of times this article has been viewed

\section{Yan Xiong \\ Yun Lang \\ Chongqi Tu \\ Hong Duan \\ Department of Orthopedics, West China Hospital, Sichuan University, Chengdu, People's Republic of China}

Correspondence: Hong Duan

Department of Orthopedics, West China Hospital, Sichuan University, No 37, Guo Xue Lane, Chengdu, Sichuan 610064,

People's Republic of China

Tel +8628 85422570

Fax +86 2885422570

Email duanhong1970@I26.com
Abstract: The patient, a 16-year-old girl, was admitted to our hospital with complaints of right hip pain and claudication. Her past medical history indicated that 2 years earlier she had undergone enucleation of her left eye for a primary choroidal melanoma. Imaging studies revealed a osteolytic destruction with soft tissue mass involving the right hemipelvis (zone I-II). Single-photon emission computed tomography (SPECT) and positron emission tomographycomputed tomography (PET-CT) showed no other sites of metastases. Consequently, the patient underwent hemipelvic prosthesis reconstruction after tumor resection. Postoperative pathological diagnosis was metastatic malignant melanoma. Thirty months after treatment, imaging studies indicated no evidence of recurrence, and functional recovery was excellent. To our knowledge, the literature does not reveal any previously reported cases of ocular choroidal melanoma that metastasized to pelvis, meanwhile was carried out hemipelvic prosthesis reconstruction after pelvic tumor resection.

Keywords: melanoma, metastasis, pelvis, tumor, reconstruction

\section{Introduction}

Malignant melanoma is a highly malignant tumor that mostly occurs in the skin and mucosa. ${ }^{1}$ It is known for its ability to metastasize to the lymph nodes, liver, lung, and other organs, but it rarely involves bone. ${ }^{2,3}$ Definite diagnosis of metastatic melanoma depends on pathological examination. The management and treatment strategies for metastatic melanoma depend largely on the extent and stage of metastatic disease. Surgical excision, chemotherapy, and radiotherapy are the main options for its treatment. ${ }^{4}$ Malignant melanoma has a poor prognosis: advanced melanoma with distant metastases has a 5-year survival rate of 5\%-14\%.

Here we present a case of pelvis metastasis from primary choroidal melanoma, whose clinical features and treatment with hemipelvic prosthesis reconstruction after tumor resection are discussed.

\section{Case report}

\section{The general information}

A 16-year-old girl presented to our department with complaints of right hip pain and claudication. A osteolytic destruction with soft-tissue mass involving the right hemipelvis (zone I-II, defined by Enneking and Dunham ${ }^{6}$ ) was revealed by a pelvic plain radiograph. A pelvic three-dimensional computed tomography (3D-CT) imaging scan showed tumor involvement of the ilium and acetabulum, with an extensive soft-tissue mass $9 \times 8 \times 5 \mathrm{~cm}$ in size (Figure 1). A pelvic MRI scan showed low T1 signal intensity 


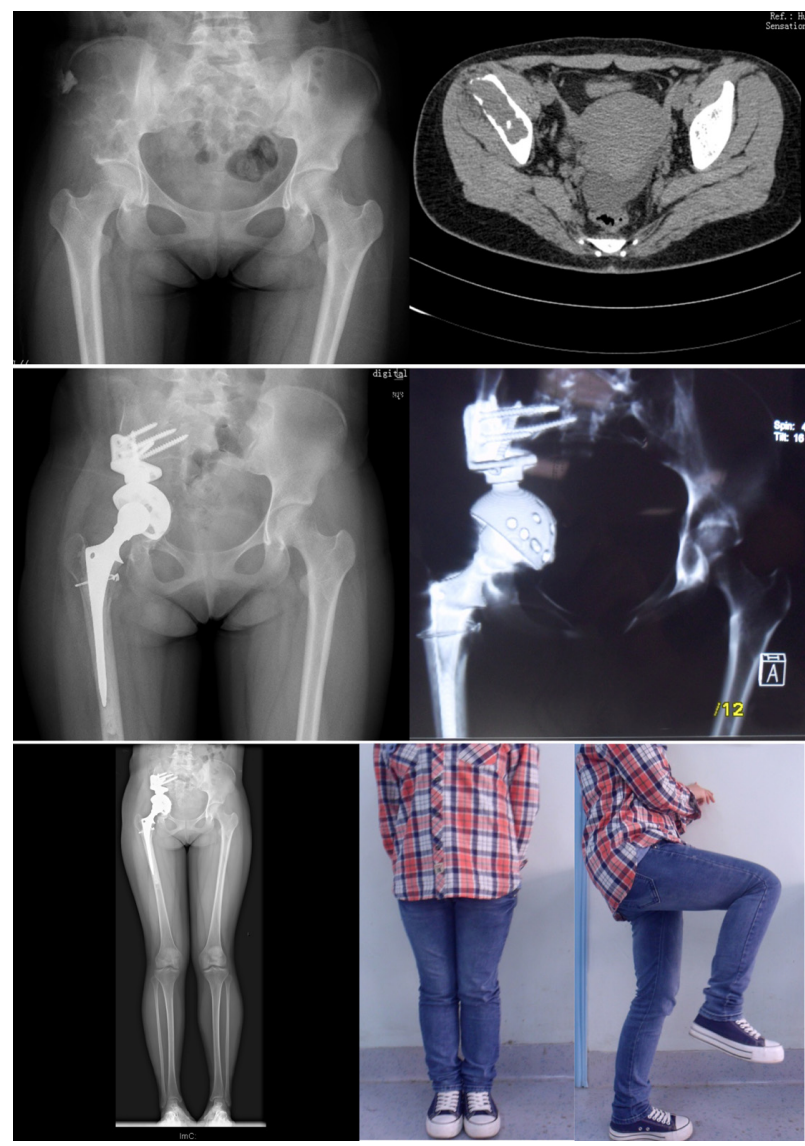

Figure I Images from before and after surgery for pelvic metastasis.

Notes: Osteolytic destruction with soft tissue mass involving the right hemipelvis (zone I-II) was revealed by a pelvis plain radiograph and pelvis 3D-CT imaging scan. Postoperation, the prosthetic positioning was good, with no loosening and migration observed in the latest follow-up. The Harris hip score was 85.

Abbreviation: 3D-CT, three-dimensional computed tomography.

lesion associated with destructive changes in the right ilium and acetabulum. Single-photon emission computed tomography (SPECT) and positron emission tomography-computed tomography (PET-CT) showed no evidence of other bony erosion or distant metastases. The patient's previous medical history indicated that in December 2009 she had undergone enucleation of the left eye for a primary choroidal melanoma. She was lost to follow-up and not seen again until approximately 2 years later.

A diagnosis of metastatic malignant melanoma was confirmed on the basis of the previous medical history and preoperative biopsy examination of the pelvic lesion (Figure 2). Treating a metastatic malignant pelvic tumor remains a major challenge because of the complex anatomy of the pelvis and high rate of associated complications. After taking into consideration the patient's general condition, young age, and possible surgical risks, the patient's treatment team decided to perform an en bloc resection and a limb-salvage procedure that included hemipelvic prosthesis

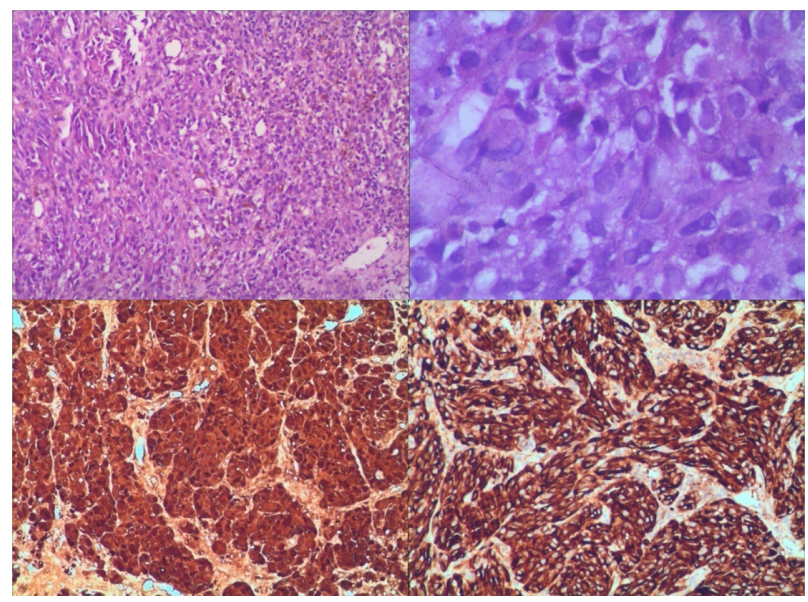

Figure 2 Preoperative biopsy of pelvic lesion.

Notes: The melanoma had a diffuse growth pattern. The cells of the tumor consisted of spindle-shaped and epithelioid cells with melanin granules scattering around the nucleus in the cytoplasm (hematoxylin and eosin, $\times 200, \times 400$ ). Immunohistochemicalstains showed positivity for HMB45, Melan-I antibodies (x200).

Abbreviation: HMB45, human melanoma black 45.

reconstruction and treatment management as described by Harrington. ${ }^{?}$

\section{Surgical technique}

A standard iliofemoral approach was used, according to the classification of pelvic resections by Enneking and Dunham. ${ }^{6}$ To reduce blood loss, lower abdominal aorta balloon occlusion was employed at the beginning of operation. ${ }^{8,9}$ An $8 \mathrm{~F}$ introducer sheath was used to place the aorta balloon below both renal arteries, so as to block the blood from the right superficial femoral artery. C-arm fluoroscopy was used to ensure proper placement. Type I-II right pelvis (ilium, periacetabular, and pubis) resection and total hip arthroplasty were performed to achieve a clear margin. During the 1-hour tumor resection surgery, the balloon was loosened and the surgical area was taken to be in adequate hemostasis. In the second surgical procedure, a modular hemipelvic replacement system from ChunLi Co (Beijing, People's Republic of China) was placed to reconstruct the right hemipelvis. Finally, the muscles and soft tissues of proximal femur were sutured into the femoral prosthesis stem to complete the in-situ restoration and functional reconstruction. As a result of the aorta balloons, the blood loss was less than $1,000 \mathrm{~mL}$ for the entire surgery.

The patient recovered well and was discharged after 12 days with no occurrence of postoperative complications. One month postsurgery, she commenced biotherapy treatment to prevent tumor recurrence. Interferon alpha- $2 \mathrm{~b} 1,500 \mathrm{wiu} / \mathrm{m}^{2}$ was injected 1-5 days per week for 4 weeks; thereafter, $900 \mathrm{wiu} / \mathrm{m}^{2}$ was injected three times a week for 11 months. 
Table I The follow-up outcomes

\begin{tabular}{|c|c|c|c|c|c|c|c|c|c|c|c|c|}
\hline & \multirow[t]{2}{*}{ VAS } & \multirow[t]{2}{*}{ Harris } & \multirow[t]{2}{*}{ MSTS93* } & \multirow[t]{2}{*}{ TESS $^{\dagger}$} & \multicolumn{8}{|c|}{ SF-36 } \\
\hline & & & & & $\overline{\mathbf{G H}}$ & PF & $\mathbf{R P}$ & BP & VT & RE & MH & Soc \\
\hline Preoperation & 8 & 39 & None & None & 25 & 30 & 20 & 10 & 30 & 35 & 20 & 25 \\
\hline Six-month follow-up & 3 & 76 & 26 & 80 & 70 & 60 & 50 & 70 & 55 & 80 & 50 & 50 \\
\hline Last follow-up & I & 85 & 28 & 90 & 90 & 85 & 80 & 80 & 80 & 85 & 90 & 85 \\
\hline
\end{tabular}

Notes: $*$ MSTS93 maximum score $=30$. ${ }^{\dagger}$ TESS maximum score $=100$.

Abbreviations: VAS, visual analog scale; Harris, Harris hip score; MSTS93, Revised Musculoskeletal Tumor Society Rating Scale; TESS, Toronto Extremity Salvage Score; SF-36, Medical Outcomes Study 36-Item Short-Form Health Survey; GH, general health; PF, physical function; RP, role physical; BP, bodily pain; VT, vitality; RE, role emotional; $\mathrm{MH}$, mental health; Soc, social function.

\section{The follow up}

Patient follow-up occurred at 1 month, 2 months, 3 months, 6 months, 9 months, 12 months, and every 6 months thereafter. Imaging studies were focused on tumor recurrence and the prosthetic situation. A visual analogue scale (VAS) was used to evaluate the degree of pain before and after the treatment. Functional outcome was determined using the Harris hip score, the Revised Musculoskeletal Tumor Society Rating Scale (MSTS93) system, ${ }^{10}$ and the Toronto Extremity Salvage Score (TESS) ${ }^{11}$ Meanwhile, the Medical Outcomes Study 36-Item Short-Form Health Survey $\left(\right.$ SF-36) ${ }^{12}$ questionnaire was used to evaluate the quality of life (show as Table 1). The patient's right-hip pain completely resolved following surgery. By 6 months postsurgery, she was quite capable of self-care, working, and going to school. Her Harris hip score, MSTS93 system score, and TESS score were excellent at the last follow up (show in Table 1). More than thirty months postsurgery, there is no sign of tumor recurrence and the prosthetic positioning is good, with no loosening or migration (Figure 1).

\section{Discussion}

Malignant melanoma accounts for $1 \%-3 \%$ of all malignancies. ${ }^{2,3}$ It occurs more frequently in young adults, with no difference by gender. ${ }^{3}$ Like other malignancies, the tumor is well known for local recurrence as well as distant metastasis. Spread occurs via lymphatics as well as the blood stream to other systemic metastasis. Reports show that advanced-stage malignant metastatic melanoma (American Joint Committee on Cancer stage IV) bears a grave prognosis, with the median survival rate of 6-9 months and 5-year survival of only $5 \%-14 \%$, in part due to a lack of effective therapy. ${ }^{5}$

For metastatic malignant melanoma, multidisciplinary approaches such as surgery, radiotherapy, adjuvant chemotherapy, and biotherapy have been administered, as have other conservative treatments. ${ }^{4}$ In previous studies, there appeared to be broad consensus that a single or local metastatic malignant melanoma lesion should be treated primarily with surgical excision. ${ }^{4,13-16}$ However, pelvic metastatic tumors remain a major surgical challenge in limb-salvage surgery because of the high rate of associated complications, including bleeding, infection, nerve damage, periprosthetic fractures, and prosthesis loosening and migration. ${ }^{13-16}$ In reported series, operations for hemipelvic resection and pelvic reconstruction took 5-10 hours, with blood loss on average of 7,000 $\mathrm{mL}$ and as high as $15,000 \mathrm{~mL}$ sometimes. ${ }^{14,17}$ As is known, the bleeding mainly occurs during pelvic tumor resection. The use of the lower abdominal aorta balloon occlusion technique in our case reduced blood loss effectively (less than 1,000 mL), which shortened the operation time to only 4 hours and also increased the opportunity for a "no touch" tumor resection, because the operation field was clear and clean.

It was important that muscles and soft tissues of the proximal femur are repaired and reconstructed in situ after tumor resection and hemipelvic prosthesis reconstruction, and that scientifically functional exercises were undertaken postoperatively to achieve encouraging outcomes. In addition, the patient's pain completely resolved following surgery (VAS score reduction from 8 to 1 ), which speeded up the period of recovery and improved quality of life. SF-36, Harris hip, MSTS93, and TESS scores were used to evaluate the recovery effects. Quality of life was first investigated by SF-36 questionnaire with our patient. Compared with the preoperative scores, follow-up scores improved and returned to nearly normal levels by the time of the last follow-up (Table 1). Functional results compared favorably with other studies, although the SF-36 was not used in those studies. ${ }^{14-16}$ The MSTS93 score of the patient in our study was 28 compared with $15.3 \pm 6.1$ in Aljassir et al. ${ }^{16}$

\section{Conclusion}

Metastasis of melanoma to the pelvis is indeed rare and has a poor prognosis. The goal of treatment is usually local control and prevention of distant metastases while preserving as much function and quality of life as possible. First-line treatment 
of a single or local metastatic malignant melanoma should be surgical excision and reconstruction.

\section{Disclosure}

The authors have nothing to disclose. The authors report no conflicts of interest in this work.

\section{References}

1. Patel SG, Prasad ML, Escrig M, et al. Primary mucosal malignant melanoma of the head and neck. Head Neck. 2002;24(3):247-257.

2. Patel JK, Didolkar MS, Pickren JW, Moore RH. Metastatic pattern of malignant melanoma. A study of 216 autopsy cases. Am J Surg. 1978;135(6):807-810.

3. Reinhardt MJ, Joe AY, Jaeger U, et al. Diagnostic performance of whole body dual modality $18 \mathrm{~F}$-FDG PET/CT imaging for $\mathrm{N}$ - and M-staging of malignant melanoma: experience with 250 consecutive patients. $J$ Clin Oncol. 2006;24(7):1178-1187.

4. Atallah E, Flaherty L. Treatment of metastatic malignant melanoma. Curr Treat Options Oncol. 2005;6(3):185-193.

5. Balch CM, Soong SJ, Gershenwald JE, et al. Prognostic factors analysis of 17,600 melanoma patients: validation of the American Joint Committee on Cancer melanoma staging system. J Clin Oncol. 2001;19(16): 3622-3634.

6. Enneking WF, Dunham WK. Resection and reconstruction for primary neoplasms involving the innominate bone. J Bone Joint Surg Am. 1978; 60(6):731-746.

7. Harrington KD. The management of acetabular insufficiency secondary to metastatic malignant disease. J Bone Joint Surg Am. 1981;63(4): 653-664.
8. Zhang L, Gong Q, Xiao H, Tu C, Liu J. Control of blood loss during sacral surgery by aortic balloon occlusion. Anesth Analg. 2007;105(3):700-703.

9. Yang L, Chong-Qi T, Hai-Bo S, et al. Appling the abdominal aortic balloon occluding combine with blood pressure sensor of dorsal artery of foot to control bleeding during the pelvic and sacrum tumors surgery. J Surg Oncol. 2008;97(7):626-628.

10. Enneking WF, Dunham W, Gebhardt MC, Malawar M, Pritchard DJ. A system for the functional evaluation of reconstructive procedures after surgical treatment of tumors of the musculoskeletal system. Clin Orthop Relat Res. 1993;(286):241-246.

11. Davis AM, Bell RS, Badley EM, Yoshida K, Williams JI. Evaluating functional outcome in patients with lower extremity sarcoma. Clin Orthop Relat Res. 1999;(358):90-100.

12. Ware JE Jr. SF-36 health survey update. Spine (Phila Pa 1976). 2000; 25(24):3130-3139.

13. Guo Z, Li J, Pei GX, Li XD, Wang Z. Pelvic reconstruction with a combined hemipelvic prostheses after resection of primary malignant tumor. Surg Oncol. 2010;19(2):95-105.

14. Zhou Y, Duan H, Liu Y, Min L, Kong Q, Tu C. Outcome after pelvic sarcoma resection and reconstruction with a modular hemipelvic prostheses. Int Orthop. 2011;35(12):1839-1846.

15. Guo W, Li D, Tang X, Ji T. Surgical treatment of pelvic chondrosarcoma involving periacetabulum. J Surg Oncol. 2010;101(2):160-165.

16. Aljassir F, Beadel GP, Turcotte RE, et al. Outcome after pelvic sarcoma resection reconstructed with saddle prosthesis. Clin Orthop Relat Res. 2005;438:36-41.

17. Simpson AH, Porter A, Davis A, Griffin A, McLeod RS, Bell RS. Cephalad sacral resection with a combined extended ilioinguinal and posterior approach. J Bone Joint Surg Am. 1995;77(3):405-411.
OncoTargets and Therapy

\section{Publish your work in this journal}

OncoTargets and Therapy is an international, peer-reviewed, open access journal focusing on the pathological basis of all cancers, potential targets for therapy and treatment protocols employed to improve the management of cancer patients. The journal also focuses on the impact of management programs and new therapeutic agents and protocols on

\section{Dovepress}

patient perspectives such as quality of life, adherence and satisfaction. The manuscript management system is completely online and includes a very quick and fair peer-review system, which is all easy to use. Visit http://www.dovepress.com/testimonials.php to read real quotes from published authors. 